\title{
Traditional used plants against cognitive decline and Alzheimer disease
}

\section{Gunter Peter Eckert*}

Department of Pharmacology, Campus Riedberg, Goethe University, Frankfurt am Main, Germany

\section{Edited by:}

Adolfo Andrade-Cetto, Universidad

Nacional Autónoma de México, Mexico

\section{Reviewed by:}

Adolfo Andrade-Cetto, Universidad

Nacional Autónoma de México, Mexico

Maria C. Revilla Monsalve, Centro

Médico Nacional, Instituto Mexicano

del Seguro Social, Mexico

${ }^{*}$ Correspondence:

Gunter Peter Eckert, Department of

Pharmacology, Campus Riedberg,

Goethe University, Biocenter N260

Max-von-Laue Street 9, 60438

Frankfurt, Germany.

e-mail: g.p.eckert@em.uni-frankfurt.de
Alzheimer's disease (AD) is a neurodegenerative disorder characterized clinically by progressive memory deficits, impaired cognitive function, and altered and inappropriate behavior. Aging represents the most important risk factor for $A D$ and the global trend in the phenomenon of population aging has dramatic consequences for public health, healthcare financing, and delivery systems in the word and, especially in developing countries. Mounting evidence obtained in in vitro and in vivo studies, suggests that various traditionally used plants in Asia, India, and Europe significantly affect key metabolic alterations culminating in AD-typical neurodegeneration. The present article aims to bring the reader up-to-date on the most recent studies and advances describing the direct and indirect activities of traditional used plants and its constituents possibly relieving features of $A D$. A variety of traditional used plants and its extracts exerted activities on $A D$ related drug targets including $A C h E$ activity, antioxidative activity, modulation of $A \beta$-producing secretase activities, $A \beta$-degradation, heavy metal chelating, induction of neurotrophic factors, and cell death mechanisms. Although pre-clinical investigations identified promising drug candidates for $A D$, clinical evidences are still pending.

Keywords: traditional plants, Alzheimer's disease, kampo, TCM, ayurveda

\section{INTRODUCTION}

Alzheimer's disease (AD) is a neurodegenerative disorder characterized clinically by progressive memory deficits, impaired cognitive function, and altered and inappropriate behavior (Mattson, 2004). $\mathrm{AD}$ represents the most common form of dementia, which places a considerable and increasing burden on patients, caregivers, and society. Aging represents the most important risk factor and dementia has become one of the major challenges in our societies due to the universal phenomenon of population aging in the world (Qiu et al., 2007). Brain regions involved in learning and memory processes, including the temporal and frontal lobes as well as the hippocampus, are reduced in size in $\mathrm{AD}$ patients as the result of degeneration of synapses and death of neurons (Arendt, 2009). AD is considered as a protein aggregation disorder, based on two key neuropathological hallmarks, namely the hyperphosphorylation of the tau protein resulting in the formation of neurofibrillary tangles (NFTs), and the increased formation and aggregation of amyloid-beta peptide $(\mathrm{A} \beta)$ derived from amyloid precursor protein (APP) (Haass and Selkoe, 2007). Although the exact underlying cause initiating the onset of $\mathrm{AD}$ is still unclear, an imbalance in oxidative and nitrosative stress, intimately linked to mitochondrial dysfunction, characterizes already early stages of AD pathology (Müller et al., 2010).

\section{ALZHEIMER - A WORLDWIDE PROBLEM WITH SPECIAL IMPACT FOR DEVELOPING COUNTRIES}

To understand neurodegenerative diseases is one of the major challenges of the twenty-first century. The United Nations estimate that the number of people suffering from age-related neurodegeneration, particularly from $\mathrm{AD}$, will exponentially increase from 25.5 million in 2000 to an estimated 114 million in 2050 (Wimo et al., 2003). Several meta-analysis have resulted in roughly similar estimates of dementia prevalence across regions. The estimated global dementia prevalence in people aged over 60 is approximate $3.9 \%$ with regional prevalence being $1.6 \%$ in Africa, $3.9 \%$ in Eastern Europe, $4.0 \%$ in China, $4.6 \%$ in Latin America, $5.4 \%$ in Western Europe, and 6.4\% in North America (Qiu et al., 2009). The global annual incidence of dementia is estimated to be around 7.5 per 1000 population (Ferri et al., 2005), with no substantial variations across continents except Africa, where incidence rates are reported to be lower than in other regions. The incidence rate of dementia increases exponentially with age and incidence rates across regions of dementia are quite similar (Qiu et al., 2007, 2009). The risk of $\mathrm{AD}$ grows exponentially with age, doubling approximately every 5-6 years (Ziegler-Graham et al., 2008). The largest increase in absolute numbers of old persons will occur in developing countries; it almost triples from 249 mio in 2000 to an estimated 690 mio in 2030. The developing regions' share of the worldwide aging population will increase from 59 to $71 \%$ (Qiu et al., 2007). Most people with dementia live in developing countries (60\% in 2001). Rates of increase are not uniform; numbers in developed countries are estimated to double between 2001 and 2040, but by more than 300\% in India, China, and their south Asian and western Pacific neighbors (Ferri et al., 2005). Hence, the global trend in the phenomenon of population aging has dramatic consequences for public health, healthcare financing, and delivery systems in the word and, especially in developing countries (Qiu et al., 2007).

\section{TREATMENT OF ALZHEIMER'S DISEASE - FROM MEDICAL CHEMISTRY TO PLANTS}

The current standard of care for mild to moderate $\mathrm{AD}$ includes treatment with acetylcholine esterase inhibitors, such as donepezil or rivastigmine, to improve cognitive function. The NMDA 
( $N$-methyl-D-aspartate) antagonist memantine has also been shown to improve cognitive function in patients with moderate to severe AD (Citron, 2010). Nimodipine, an L-type calcium current blocker or piracetam, a nootropicum, almost complete the list of non-alternative drugs to treat AD (Tsolaki et al., 2001; Evans et al., 2004). In addition, common non-cognitive neuropsychiatric symptoms, such as mood disorder, agitation, and psychosis often require the introduction of medication, even tough no existing drug is specifically indicated for their management. However, there is no approved treatment with a proven disease-modifying effect (Citron, 2010) and interventions with current drugs, if started early enough, may at best slow down the fatal pathophysiological alterations leading to manifestation of clinical AD symptoms, but are unable reverse the neurodegenerative process.

Beside synthetic drugs, a variety of AD related medicine originates from traditionally used plants. In this respect, Ginkgo biloba and galantamine represent the most famous cases.

\section{GINKGO BILOBA-FROM TRADITIONAL CHINESE MEDICINE TO A STANDARDIZED DRUG}

Originally, Ginkgo biloba (Coniferae) has been traditionally used for respiratory disorders in China and to improve memory loss associated with blood circulation abnormalities in Iran (Howes et al., 2003). This herb has been subjected to numerous investigations regarding its potential in cognitive disorders. Standardized extracts, particularly EGb 761, derived from the plants' leaves are successfully used as herbal drug for the improvement of cognitive and memory impairment (for review see Kumar, 2006). EGb 761 represents a prototype of plant extracts for attenuating CNS disorders, due to the fact that both flavonoids and terpenic lactones, which are partly also present in numerous other plant extracts, have been identified as the active principles in Ginkgo extracts as well as the ample experimental evidence on EGb 761's protective efficiency in vitro and in vivo. The potential of EGb 761 to attenuate the cytotoxic effects of Alzheimer's related neurotoxic amyloid peptides when added to the culture medium was demonstrated not only in neuronal-like cell lines but also primary neurons, though with different efficiency (Bastianetto et al., 2000; Yao et al., 2001; Eckert et al., 2005). The impact of Ginkgo extract has been largely attributed to its antioxidant activity (Yao et al., 2001). The effects of oxidative stress were reduced in lymphocytes and brain cells derived of EGb 761-treated AD-transgenic and non-transgenic mice (Schindowski et al., 2001; Abdel-Kader et al., 2007). Recent data, however, indicate that EGb 761 also affects the production of neurotoxic beta-amyloid peptides $(A \beta)$, for example, by upregulating $\alpha$-secretase activity both in cells and animals (AbdelKader et al., 2007).

In aged and/or $\mathrm{AD}$ transgenic mice, EGb 761 treatment resulted in improved memory compared to control animals (Stoll et al., 1996; Tang et al., 2002). The mechanisms responsible for latter observation are still a matter of debate. Whereas Luo et al. (2003) reported changes in APP load in rats treated with Ginkgo extract (100 mg/kg b.w.) for 15 days, Garcia-Alloza et al. (2006) suggested changes in the extent of oxidative stress to account for the neuroprotection in EGb 761-fed AD mice. Interestingly, the EGb 761associated reduction in $A \beta$ plaque-linked oxidative stress in mice brain was unaffected by plaque size or number. Similarly, Tg2576 transgenic mice benefited from repeated EGb 761 oral intake, evident by improved spatial memory, although soluble and $A \beta$ plaque burden was unaffected (Stackman et al., 2003). Paradoxically, protein oxidation increased in Ginkgo-treated animals (Stackman et al., 2003). The authors speculated that metabolic alterations, mediated by vasodilatory and tropic effects of EGb 761, might be responsible for this finding.

New promising targets for better understanding the molecular mode of EGb 761 action arises from microarray studies. Ginkgo supplementation ( $300 \mathrm{mg} / \mathrm{kg}$ diet) induced differential changes in mRNA expression in mouse hippocampus and cortex. Noteworthy, in the cortex, mRNA for neuronal tyrosine/threonine phosphatase 1 and microtubule-associated Tau were significantly enhanced. Both proteins are associated with the formation as well as breakdown of toxic, AD-typical NFTs (Watanabe et al., 2001).

Recently, the safety and effectiveness of a traditional Ginkgo fresh extract was tested clinically (Baurle et al., 2009). The tested patients suffered from age-related mild cognitive impairment of the non-Alzheimer type. About half of all patients experienced an improvement in their memory and their ability to concentrate, as well as a decrease in symptoms of forgetfulness. The holistic fresh Ginkgo extract was found to be safe and, at least, adjuvant treatment option for patients with mild cognitive impairments (Baurle et al., 2009).

In a nutshell, many placebo-controlled clinical trials proved G. biloba to be a useful herbal remedy for attenuating symptoms in dementia, with efficiency comparable to those of standard drugs in $\mathrm{AD}$ treatment (Le Bars, 2003). This notion has been confirmed in a recent 3-month study in comparison to donepezil (Mazza et al., 2006). Furthermore, EGb 761 has been suggested to prevent neurodegenerative pathologies (Christen, 2004). The ongoing GuidAge study, a double-blind randomized trial, will shed further light on the efficiency of EGb 761 in the prevention of $\mathrm{AD}$ (Andrieu et al., 2008).

\section{GALANTAMINE - FROM FOLK TO MODERN MEDICINE}

Galantamine is an alkaloid known form several members of the Amaryllis family (Amaryllidaceae), and the idea for developing a medical product for $\mathrm{AD}$ from these species seems to be based on the local use of one of these species in a remote part of Europe. It has become an important therapeutic options used to slow down the process of neurological degeneration in $\mathrm{AD}$. Its development from little known observational studies in the Caucasus Mountains (Southern Russia), to the use of this drug in Eastern European countries (esp. Bulgaria) in the treatment of poliomyelitis and ultimately to the recent introduction onto Western markets in the treatment of AD (Heinrich, 2010). Galantamine was first isolated from snowdrop (Galanthus spp.) but today it is obtained from Narcissus spp. and Leucojum spp. as well as synthetically (Heinrich and Lee Teoh, 2004). According to unconfirmed reports, in the 1950s, a Bulgarian pharmacologist noticed the use of the common snowdrop growing in the wild by people who were rubbing it on their foreheads to ease nerve pain. Also, some of the earlier publications indicate the extensive use of snowdrop in Eastern Europe, such as Romania, Ukraine, the Balkan Peninsula, and in the Eastern Mediterranean countries. However, Mashkovsky and KruglikovaLvov (1951) published the first work that establishes the acetyl- 
choline esterase inhibiting properties of galantamine isolated from Galanthus woronowii. Poliomyelitis was one of the first indications for galantamine, especially in the Eastern and Central European, since the compound enhances nerve impulse transmission at the synapse. Studies indicating blood-brain barrier penetration of the alkaloid pioneer the development of CNS-related indications. Based on the knowledge of galantamine in both the peripheral and central nervous system, many countries in Eastern Europe used it as an acknowledged treatment in Myasthenia gravis and muscular dystrophy, residual poliomyelitis paralysis symptoms, trigeminal neurologica, and other forms of neuritis. A crucial step for the success of galantamine as a medicine against $\mathrm{AD}$ was based on the synthesis developed in the mid-1990s. The scientific rationale for using cholinesterase inhibitors in the management of $\mathrm{AD}$ is based on the cholinergic hypothesis. Impairment of the central cholinergic system represents one hallmark of $\mathrm{AD}$, which is characterized by loss of cholinergic neurons in the forebrain and a marked decrease in the activity of choline acetyltransferase. Overall, galantamine represents an example for the successful ethnobotanydriven development of a natural product into a clinically important drug (Heinrich, 2010).

In the last years, focus on $\mathrm{AD}$ drug discovery is shifting away from AChE inhibitors and a large number of other targets are currently being explored.

However, mounting evidence obtained in vitro and in vivo, suggests that various traditionally used plants significantly affect key metabolic alterations culminating in AD-typical neurodegeneration. While the impact of the aforementioned traditional used plants on $\mathrm{AD}$ has been reviewed comprehensively (Howes et al., 2003; Houghton and Howes, 2005; Akhondzadeh and Abbasi, 2006; Yan et al., 2007), the purpose of the present article is to bring the reader up-to-date on the most recent studies and advances describing the direct and indirect activities of plant constituents possibly relieving features of $\mathrm{AD}$. Recently tested $\mathrm{AD}$ related drug targets include AChE activity (Oh et al., 2004; Joshi and Parle, 2006; Ren et al., 2006; Lin et al., 2008; Vasudevan and Parle, 2009), antioxidative activity (Pendry et al., 2005; Lee et al., 2007; Dhanasekaran et al., 2009), modulation of A $\beta$-producing secretase activities (Fujiwara et al., 2006, 2009; Dhanasekaran et al., 2009; Lv et al., 2009; Wang and Du, 2009; Zhou et al., 2009), A $\beta$-degradation (Lee et al., 2007; Yang et al., 2009), heavy metal chelating (Ren et al., 2006), neurotrophic factors (Yabe et al., 2003), and cell death mechanisms (Yu et al., 2005; Table 1).

The majority of recent reports on plants with traditional uses and activities relevant for $\mathrm{AD}$ originate from the traditional Chinese and Oriental Medicine, as well as from Kampo Ayurveda and Mediterranean traditional knowledge.

\section{PLANTS FROM TRADITIONAL ASIAN MEDICINE}

Ginseng products are popularly referred to as "adaptogen," which connotes that these products purportedly increase to physical, chemical, and biological stress and builds up general vitality, including physical and mental capacity for work. Panax ginseng roots are traditionally taken orally as adaptogens, aphrodisiacs, nourishing stimulants, and in the treatment of sexual dysfunction in men. The fresh root, can be directly chewed, or soaked in various wines for a period of time before drinking or chewing. Ginseng is most often available either in whole or sliced dried form. However, usually ginseng is used at subclinical doses for a short period and as such, it does not produce measurable medicinal effects (Jia et al., 2009). Panax notoginseng is widely used in traditional Chinese medicine (TCM) to improve learning and memory (Wang and Du, 2009). Moreover, protective actions against cerebral ischemia, beneficial effects on the cardiovascular system, and haemostatic, antioxidant, hypolipidemic, hepatoprotective, renoprotective, and estrogen-like activities have been described (Ng, 2006).

Ginsenoside Rg1, a major active component of sanchi ginseng ( $P$. notoginseng), was shown to inhibit $\beta$-secretase activity in vitro, to protect PC12 cells against $\mathrm{A} \beta_{25-35}$ (Wang and Du, 2009), and to exert neuroprotective effects (Jia et al., 2009). It has to be noted that Wang and Du (2009) treated neuronal-like cells with excessive $\mathrm{A} \beta$ concentrations of $50 \mu \mathrm{M}$ for $48 \mathrm{~h}$.

Ginsenoside $\mathrm{Rg} 3$, one of the major active components of sanchi ginseng significantly reduced the levels of $A \beta_{1-40}$ and $A \beta_{1-42}$ in SK-N-SH cells transfected with Swedish mutant beta-APP. Enhanced $A \beta$ degradation is due to Ginsenoside Rg3-induced neprilysin expression (Yang et al., 2009), which represents the ratelimiting enzyme in A $\beta$ degradation (Iwata et al., 2000).

Akebia saponin $B$ was found to antagonize $A \beta_{25-25}$ toxicity in PC12 cells (Zhou et al., 2009). Akebia saponin B belongs to the saponin fraction of a water extract from Dipsacus Asper Wall. This plant is a well-known TCM for enhancing kidney activity and the rational to test this pant for $\mathrm{AD}$ originates form the idea that according to TCM, the etiopathogenesis of AD lies in kidney deficiency during aging (Zhou et al., 2009).

Penta-O-galloyl-beta-D-glucopyranose (PGG), a major component of the traditional herb Paenoia suffruticosa Andrews (Moutan Cortex), inhibits A $\beta$ fibril formation and destabilizes preformed A $\beta$ fibrils in a concentration dependent matter (Fujiwara et al., 2009). Moreover, the herb improved long-term memory impairment in an $\mathrm{AD}$ mouse model and inhibited $\mathrm{A} \beta$ accumulation in brains of treated mice (Fujiwara et al., 2009). The traditional Chinese herb Moutan Cortex is commonly used to treat inflammatory and pyretic disorders (Hsieh et al., 2006) and possess potent antioxidant, antimutagenic, and antiproliferative effects (Choi et al., 2002). It was earlier reported that PGG could protect neuronal cells from oxidative stress by induction of $\mathrm{HO}-1$ gene expression (Choi et al., 2002).

Tenuifolin, a crude extract derived from Polygala tenufolia Willd (Polygalaceae) (PTW) was found to decrease A $\beta$ secretion from transfected cells, probably due to inhibition of the beta-site APP cleaving enzyme (Lv et al., 2009). Treatment of rat cortical neurons with PTW enhanced axonal length dose-dependently after $A \beta_{25-35^{-}}$ induced axonal atrophy. However, dendritic atrophy and synaptic loss induced by $A \beta_{25-35}$ were not recovered after treatment with PTW extract. In contrast, $A \beta_{25-35}$-induced cell damage was completely inhibited by PTW extract (Naito and Tohda, 2006). PTW is classically mentioned as an anti-dementia drug in Chinese and Japanese traditional medicine (Naito and Tohda, 2006). It has been shown that PFW can improve hippocampus-dependent learning and memory, possibly through improvement of synaptic transmission, activation of the MAP kinase cascade, and enhancement BDNF levels (Xue et al., 2009). Accordingly, PTW up-regulated the expression of BDNF and TrkB mRNA to promote the recovery 
Table 1 | Summary of Plants and its constitutes with traditional use tested recently in vitro, in vivo and in clinical trails for Alzheimer's disease (AD).

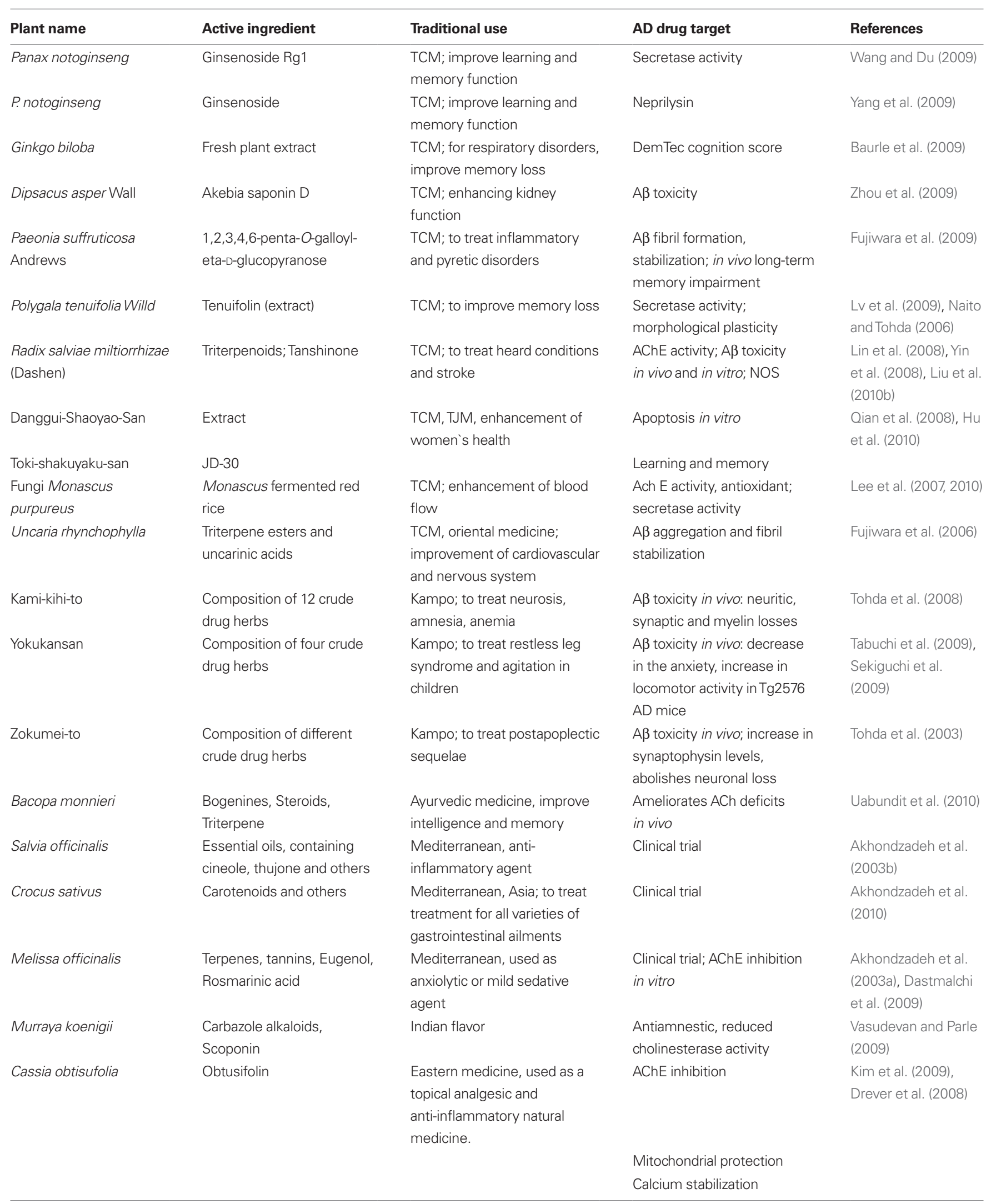


Table 1 | Continued

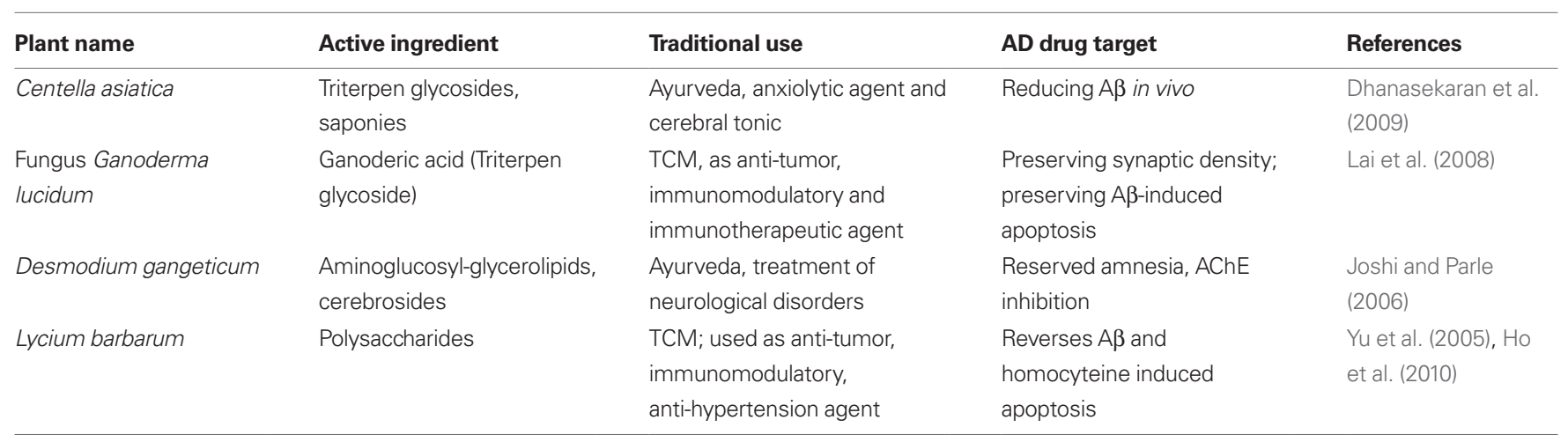

of the neurons from chronic stress-induced damages (Sun et al., 2009). The methanol fraction of an ethanolic extract from PTW showed antagonistic action on neurotoxicity induced by glutamate and serum deficiency in PC12 cells (Li et al., 2008a). Some of the active ingredients of PTW are oligosaccharide esters, which provide a high in vivo antioxidant activity in senescence-accelerated mice (Liu et al., 2010a).

Recently, Lin et al. (2008) have tested the anti-acetylcholinesterase activities of aqueous and ethanolic extracts of various TCM. Ethanolic extracts from Caulis spatholobi, Radix paeoniae alba, and Radix salvia miltiorrhizae were found to have the strongest AChE inhibitory activity as indicated by $\mathrm{IC}_{50}$ values lower than $10 \mu \mathrm{g} / \mathrm{ml}$ extract. The most active extract from Radix salviae miltiorrhizae was further fractionated and found that AChE inhibition is due to the presence of two triterpenoids (Lin et al., 2008) confirming earlier data (Ren et al., 2004). Yin et al. (2008) tested the effect of phenanthrofurane quinone derivatives of salviae miltiorrhizae triterpenoids known as tanshinones on the levels of nitric oxide synthase and AChE in brains of an $\mathrm{AD}$ rat model. In TCM radix salviae miltiorrhizae (Danshen) is used to prevent and treat heart conditions and strokes (Li et al., 2008b). Tanshinone modulates AChE and NOS protein concentrations in the hippocampus of cranial $A \beta_{1-42}$ injected rats (Yin et al., 2008). Recently, the neuroprotective effects of tanshinone was demonstrated in cortical neurons (Liu et al., 2010b). Pretreatment of the cells with Tanshinone prior to $A \beta_{25-35}$ exposure suppressed $\mathrm{A} \beta$-induced cellular events, such as loss in viability, apoptosis, decrease in superoxide dismutase, and glutathion peroxidase activity, increased ROS and decreased mitochondrial membrane potential (Liu et al., 2010b).

Danggui-Shaoyao-San (DSS; Tangkuei or Peony Powder) (TokiShakuyaku-San, TSS in Japanese), used as TCM and TJM for centuries for the enhancement of women's health, e.g., for gynecological and obstetrical purposes (Qian et al., 2008). In early studies it was shown that a powdered extract of DSS ameliorates dysfunction of the central cholinergic nervous system and scopolamine-induced decrease in ACh levels in mouse brain (Itoh et al., 1996). In another study the effects of aqueous extract of Danggui-Shaoyao-San on naturally aged mice were examined to investigate the pharmacological basis for its therapeutic efficacy on senile dementia. In agreement with earlier data (Komatsu et al., 1999) the results showed that DSS improves impaired cognitive function of aged mice. Results indicated that DSS ameliorates age-related memory dysfunction, modulates metabolism of monoamine neurotransmitters, and protects ultra structure of the cortex (Kou et al., 2005). These findings suggest that DSS may be a useful therapeutic agent for senile dementia, especially AD (Kou et al., 2005). Accordingly, in a recent in vitro study, DSS exhibits anti-apoptotic effects after challenging PC12 cells with hydrogen peroxide: the compound counteracts the down regulation of anti-apoptotic $\mathrm{BCl}-2$ protein, the upregulation of pro-apoptotic Bax protein, the release of mitochondrial cytochrome $c$, and sequential activation of caspases (Qian et al., 2008). Moreover, DSS significantly reduced the $A \beta_{25-35}$-induced neuronal death and the lipid peroxidation in vivo (Egashira et al., 2005). Accordingly, the DSS extract JD-30 ameliorated $\mathrm{A} \beta_{25-35}$ induced impairment of spatial learning and memory in mice, as well as inhibition of long-term potentiation (LTP) in the hippocampus (Hu et al., 2010).

The seeds of Cassia obtisufolia (Fabaceae) have long been used in traditional eastern medicine and more recently the ethanolic fraction of the seeds has been shown to attenuate memory in mice (Kim et al., 2009). Cassia obtisufolia extract (COE) attenuated calcium dysregulation and promoted mitochondrial protection in mouse primary hippocampal cultures. However, COE had no effect on cell death induced by incubation with oligomeric $A \beta$ (Drever et al., 2008). Gluco-obtusifolin, isolated from the seeds of C. obtusfolia L., and its aglycone, obtusifolin, was found to inhibit acetylcholinesterase activity in vitro and ex vivo (Kim et al., 2009). However, a recent study reported C. obtusfolia related hepatotoxicity in chronic hepatitis B patients (Yuen et al., 2006).

Lycium barbarum (Solanaceae; Wolfberry) is a fruit that is known for its eye-protective and anti-aging properties in Asian countries (Ho et al., 2010). Recent in vitro investigations evaluated that pretreatment of rat cortical neurons with an extract isolated from L. barbarum significantly reduced the release of lactate dehydrogenase $(\mathrm{LDH})$. In addition, it attenuated $\mathrm{A} \beta$ peptide-activated caspases-3-like activity by reduced phosphorylation of JNK-1 and its substrates c-Jun (Yu et al., 2005). Recently, polysaccharides were identified as active ingredient of $L$. barbarum that provides protective properties against $A \beta$ and homocysteine (Ho et al., 2010).

Uncaria rhynchophylla (Rubiaceae) has been used as a TCM for cardiovascular and neurological diseases (Chou et al., 2009) and for convulsive disorders in Oriental medicine (Lee et al., 2003). Triterpene esters and uncarinic acids $\mathrm{C}$ and $\mathrm{D}$ were identified as 
active components of U. rhynchophylla (Shi et al., 2003; Lee et al., 2008; Umeyama et al., 2010). The alkaloids of U. rhynchophylla mainly act on the cardiovascular and central nervous system including hypertension, brachycardia, antiarrhythmia, and protection of cerebral ischemia and sedation. The active mechanisms were related to blocking of calcium channels, opening of potassium channels, and regulating of nerve transmitters transport and metabolism (Shi et al., 2003) as well as suppression of c-Jun N-terminal kinase (JNK) phosphorylation (Hsieh et al., 2009). U. rhynchophylla significantly inhibited NMDA receptor-activated ion currents in acutely dissociated hippocampal CA1 neurons in cultured brain slices (Lee et al., 2003). Moreover, anxiolytic effects of the aqueous extract of U. rhynchophylla were reported (Jung et al., 2006). In view to $A D, U$. rhynchophylla intensively inhibited $A \beta$ aggregation and significantly destabilized preformed $A \beta_{1-40}$ and $A \beta_{1-42}$ fibrils (Fujiwara et al., 2006).

Kami-kihi-to a TCM (Jia-Wei-Gui-Pi-Tang), which is composed of 12 crude herbs also used in Japanese kampo tradition. It has been used to treat neurosis, amnesia, anemia, and some other diseases (Nishizawa et al., 1994). Kampo uses fixed combinations of herbs in standardized proportions according to the classical literature of Chinese medicine. Today in Japan, Kampo is integrated into the Japanese health care system (Dharmananda, 2004). Clinically, Kihi-to may improve chronic immune thrombocytopenic purpura (Yamaguchi et al., 1993). However, possible adverse effects on glycemia were reported (Kawasaki et al., 2000). Recently, effects of Kihi-to on memory deficits and losses of neuritis and synapses were examined using $\mathrm{AD}$ mice. Short time administration of Kihi-to resulted in marked improvements of $A \beta_{25-35}$ induced impairments in memory in mice. Kihi-to was shown to attenuate neuritic, synaptic, and myelin losses in brain of cranial $A \beta$ injected mice (Tohda et al., 2008). An aqueous extract of Ganoderma lucidum (Ganodermataceae; Lingzhi mushroom; GLE), a medicinal fungus used clinically in many Asian countries to promote health and longevity was also shown to attenuate $A \beta$-induced synaptotoxcitiy by preserving the synaptic density protein, synaptophysin (Lai et al., 2008). In addition, GLE antagonized A $\beta$-triggered proapoptotic caspase cleavage and attenuated c-JNK phosphorylation (Lai et al., 2008).

Yokukansan (Yi-ga-san), a remedy composed of four herbs, traditionally used for restlessness and agitation in children (Tsuyoshi and Jun, 2009), has in recent times attracted attention as drug to treat dementia including AD (Maruyama et al., 2006; de Caires and Steenkamp, 2010). The results of a recent pilot study indicated that Yokukansan can alleviate the behavioral symptoms of frontotemporal dementia (Kimura et al., 2010). An open-label study suggested that Yokukansan might be effective in the treatment of behavioral and psychological symptoms of dementia (Hayashi et al., 2010). Evidences for a possible mode of action comes from two recent preclinical studies: Yokukansan reduces aggressiveness without suppressing physical activity in mice injected intracerebroventricular with $\mathrm{A} \beta_{25-35}$ (Sekiguchi et al., 2009). Using an AD mouse model Tabuchi et al. (2009) demonstrated that Yokukansan ameliorates learning deficits and non-cognitive defects including a decrease in the anxiety and an increase in locomotor activity observed in $\operatorname{Tg} 2576$ mice.
Only few studies of Zokumei-to used as Kampo in Japanese medicine for postapoplectic sequelae have been carried out (Tohda et al., 2003). Kamatsu and coworkers generated pre-clinical evidence for Zokumei-to as possible drug for $\mathrm{AD}$ (Tamura et al., 2002). Treatment of mice intracerobroventricularly injected with $A \beta_{25-35}$ showed beneficial effects on memory impairment and synaptic loss after Zokumei-to treatment (Tohda et al., 2003).

Monascus-fermented red mold rice (RMR), a TCM and health food, include monacolins and multifunctional metabolites. RMR is traditionally used for improvement of blood circulation (Ma et al., 2000). Preparation of RMR following ancient methods by fermenting the fungal strain Monascus purpureus Went on moist and sterile rice indicated the presence of a group of metabolites belonging to the monacolin family of polyketides, together with fatty acids, and trace elements. The presence of these compounds may explain in part the cholesterol-lowering ability associated with this traditional Chinese food (Ma et al., 2000). Monacolins, like statins, affect lipid homeostasis by inhibition HMG-CoA reductase the rate-limiting enzyme in cholesterol biosynthesis (Wang and Lin, 2007; BarriosGonzalez and Miranda, 2010). Accordingly, oral administration of Monascus powder in hyperlipidemic hamsters proved to decrease TC, TG, and LDL-C levels (Lee et al., 2006). In vitro studies indicated that ethanolic RMR extract provides stronger neuroprotection in rescuing cell viability as well as repressing inflammatory response and oxidative stress. RMR administration to mice potently reverses the memory deficit in the memory task. Moreover, in vivo RMR potently reversed $A \beta_{1-40}$ infusion induced acetylcholinesterase activity, reactive oxygen species, and lipid peroxidation and increases total antioxidant status and superoxide dismutase activity in brain. Compared to lovastatin the protective activities of RMR was more significant (Lee et al., 2007). A recent study showed that RMR provided neuroprotection by reduction of $A \beta_{1-40}$ formation and deposition due to suppressing the cholesterol-raised betasecretase activity and apolipoprotein E expression. Moreover, RMR mediated the proteolytic process of APP toward neuroprotective sAPP $\alpha$ secretion in hippocampus (Lee et al., 2010).

\section{PLANTS FROM TRADITIONAL ORIENTAL MEDICINE}

Bacopa monnieri (Scrophulariaceae) has been used in the traditional system of Ayurvedic medicine to improve intelligence and memory (Uabundit et al., 2010). A randomized, double-blind, placebo-controlled trial provides further evidence that $B$. monnieri has potential for safely enhancing cognitive performance in the aging (Calabrese et al., 2008). Recent in vivo studies identified neuroprotective effects in a rat model of AD: escape latency time in Morris water maze test was improved and the reduction of neurons was mitigated after B. monnieri treatment (Uabundit et al., 2010).

Murraya koenigii (Rutaceae) leaves commonly known as curry patta are added routinely to Indian gravy and vegetarian dishes as favorite condiment (Vasudevan and Parle, 2009). The leaves of $M$. koenigii are also used as Ayurvedic medicine as antimicrobial, anti-inflammatory, hepatoprotective, anti-hypercholesterolemic, or anti-inflammatory remedy (Xie et al., 2006; Arulselvan and Subramanian 2007; Birari et al., 2010). Diets composed of M. koenigii leaves significantly improved memory scores and reduced amnesia induced by scopolamine and diazepam in young 
and aged mice in a dose dependent manner (Vasudevan and Parle, 2009). Moreover, brain cholinesterase activity and total cholesterol were reduced.

Centella asiatica (Gotu Kola; Mackinlayaceae) is used as leafy green in Sri Lankan cuisine and beside others used medicinally as anxiolytic agent and as cerebral tonic (Bradwejn et al., 2000). Earlier findings indicated that an aqueous extract of $C$. asiatica is effective in preventing the cognitive deficits, as well as the oxidative stress, caused by intracerebroventricular injection of streptozotocin in rats (Veerendra Kumar and Gupta, 2003). Subsequent studies in neuroblastoma cells expressing A $\beta$ identified the ERK/RSK signaling pathway to be involved in a possible molecular mechanism for memory enhancing property of Gotu Kola extract (Xu et al., 2008). Recently, C. asiatica extract was found to selectively decrease hippocampal $\mathrm{A} \beta$ levels in AD mouse model expressing the Swedish' APP and the M146L presenilin 1 mutations (Dhanasekaran et al., 2009).

Desmodium gangeticum (Fabaceae) commonly known as Salparni, is widely used in ayurveda for the treatment of neurological disorders (Joshi and Parle, 2006). An aqueous extract of Desmodium gangeticum (DGE) was shown to significantly improve learning and memory in mice and reversed the amnesia induced by both, scopolamine and natural aging. DGE also decreased whole brain acetylcholinesterase activity (Joshi and Parle, 2006).

\section{PLANTS WITH TRADITIONAL EUROPEAN USE}

Salvia officinalis (Sage; Lamiaceae) traditionally used, e.g., in tea preparations as anti-inflammatory agent, recently attract attention as beneficial in dementia (Kennedy and Scholey, 2006). Sage protects PC12 cells from A $\beta_{1-42}$ induced neurotoxicity, which include reactive oxygen species formation, lipid peroxidation, DNA fragmentation, caspase-3 activation, and tau protein hyperphosphorylation (Iuvone et al., 2006). These in vitro findings may help to elucidate Sage's clinical effects: S. officinalis extract was tested in patients with mild to moderate $\mathrm{AD}$ in a double-blind, randomized and placebocontrolled multi-center trial in Iran (Akhondzadeh et al., 2003b; Akhondzadeh and Abbasi, 2006). At 4 months, S. officinalis extract produced a significant better outcome on cognitive functions than placebo (Akhondzadeh et al., 2003b). Using comparable clinical settings Akhondzadeh et al. (2003a) also reported beneficial effects for the traditional used remedies Crocus sativus (Iridaceae), traditionally used to treat all varieties of gastrointestinal ailments and Melissa officinalis (Lamiaceae) traditionally used, e.g., as an anxiolytic or mild sedative agent (Akhondzadeh et al., 2010). Recent screening assays identified rosmarinic acid from $M$. officinalis extracts to potently inhibit AChE (Dastmalchi et al., 2009).

\section{CONCLUSION}

Although advances have been made in unrevealing AD neuropathology, only few treatment options currently exist. Various potential therapeutic or preventive compounds have been tested in clinical trials, yet most have failed to show a clear therapeutic benefit. The lack of effective therapies in connection with the predicted dramatic increase in $\mathrm{AD}$ cases in the coming decades evoke the demand on new drug candidates. Numerous direct and indirect activities of traditional used plants and its constituents that relieve features of $\mathrm{AD}$ have been reported recently. Although pre-clinical investigations identified promising drug candidates for $\mathrm{AD}$, clinical evidences are still pending and it can be doubted that the track record of Galantamin or G. biloba extract will be repeated in the near future.

\section{REFERENCES}

Abdel-Kader, R., Hauptmann, S., Keil, U., Scherping, I., Leuner, K., Eckert, A., and Müller, W.E. (2007). Stabilization of mitochondrial function by Ginkgo biloba extract (EGb 761). Pharmacol. Res. 56, 493-502.

Akhondzadeh, S., and Abbasi, S.H. (2006). Herbal medicine in the treatment of Alzheimer's disease. Am. J. Alzheimers Dis. Other Demen. 21, 113-118.

Akhondzadeh, S., Noroozian, M., Mohammadi, M., Ohadinia, S., Jamshidi, A. H., and Khani, M. (2003a). Melissa officinalis extract in the treatment of patients with mild to moderate Alzheimer's disease: a double blind, randomised, placebo controlled trial. J. Neurol. Neurosurg. Psychiatr. 74, 863-866.

Akhondzadeh, S., Noroozian, M., Mohammadi, M., Ohadinia, S., Jamshidi, A. H., and Khani, M. (2003b). Salvia officinalis extract in the treatment of patients with mild to moderate Alzheimer's disease: a double blind, randomized and placebocontrolled trial. J. Clin. Pharm. Ther. 28, 53-59.
Akhondzadeh, S., Shafiee Sabet, M., Harirchian, M. H., Togha, M., Cheraghmakani,H., Razeghi,S.,Hejazi, S. S., Yousefi, M. H., Alimardani, R., Jamshidi, A., Rezazadeh, S. A., Yousefi, A., Zare, F., Moradi, A., and Vossoughi, A. (2010).A22-week, multicenter, randomized, double-blind controlled trial of Crocus sativus in the treatment of mild-to-moderate Alzheimer's disease. Psychopharmacology (Berl.) 207, 637-643.

Andrieu, S., Ousset, P. J., Coley, N., Ouzid, M., Mathiex-Fortunet, H., and Vellas, B. (2008). GuidAge study: a 5-year double blind, randomised trial of EGb 761 for the prevention of Alzheimer's disease in elderly subjects with memory complaints. i. rationale, design and baseline data. Curr. Alzheimer Res. 5, 406-415.

Arendt, T. (2009). Synaptic degeneration in Alzheimer's disease. Acta Neuropathol. 118, 167-179.

Arulselvan, P., and Subramanian, S. P. (2007). Beneficial effects of Murraya koenigii leaves on antioxidant defense system and ultra structural changes of pancreatic beta-cells in experimental diabetes in rats. Chem. Biol. Interact. 165, 155-164.

Barrios-Gonzalez, J., and Miranda, R. U. (2010). Biotechnological production and applications of statins. Appl. Microbiol. Biotechnol. 85, 869-883.

Bastianetto, S., Ramassamy, C., Dore, S., Christen, Y., Poirier, J., and Quirion, R. (2000). The Ginkgo biloba extract (EGb 761) protects hippocampal neurons against cell death induced by beta-amyloid. Eur. J. Neurosci. 12, 1882-1890.

Baurle, P., Suter, A., and Wormstall, H. (2009). Safety and effectiveness of a traditional ginkgo fresh plant extractresults from a clinical trial. Forsch. Komplementmed. 16, 156-161.

Birari, R., Javia, V., and Bhutani, K. K. (2010). Antiobesity and lipid lowering effects of Murraya koenigii (L.) Spreng leaves extracts and mahanimbine on high fat diet induced obese rats. Fitoterapia 81, 1129-1133.

Bradwejn, J., Zhou, Y., Koszycki, D., and Shlik, J. (2000). A double-blind, placebo-controlled study on the effects of Gotu Kola (Centella asiatica) on acoustic startle response in healthy subjects. J. Clin. Psychopharmacol. 20, 680-684.

Calabrese, C., Gregory, W. L., Leo, M., Kraemer, D., Bone, K., and Oken, B. (2008). Effects of a standardized Bacopa monnieri extract on cognitive performance, anxiety, and depression in the elderly: a randomized, double-blind, placebo-controlled trial. J. Altern. Complement. Med. 14, 707-713.

Choi, B. M., Kim, H. J., Oh, G. S., Pae, H. O., Oh, H., Jeong, S., Kwon, T. O., Kim, Y. M., and Chung, H. T. (2002). 1,2,3,4,6-Penta-O-galloyl-beta-Dglucose protects rat neuronal cells (Neuro 2A) from hydrogen peroxidemediated cell death via the induction of heme oxygenase-1. Neurosci. Lett. 328, 185-189.

Chou, C. H., Gong, C. L., Chao, C. C., Lin, C. H., Kwan, C. Y., Hsieh, C. L., and Leung, Y. M. (2009). Rhynchophylline from Uncaria rhynchophylla functionally turns delayed rectifiers into A-Type K+ channels. J. Nat. Prod. 72, 830-834. Christen, Y. (2004). Ginkgo biloba and neurodegenerative disorders. Front. Biosci. 9, 3091-3104. 
Citron, M. (2010). Alzheimer's disease: strategies for disease modification. Nat. Rev. Drug Discov. 9, 387-398.

Dastmalchi, K., Ollilainen, V., Lackman, P., Boije af Gennas, G., Dorman, H. J., Jarvinen, P. P., Yli-Kauhaluoma, J., and Hiltunen, R. (2009). Acetylcholinesterase inhibitory guided fractionation of Melissa officinalis L. Bioorg. Med. Chem. 17, 867-871.

de Caires, S., and Steenkamp, V. (2010). Use of Yokukansan (TJ-54) in the treatment of neurological disorders: a review. Phytother. Res. 24, 1265-1270.

Dhanasekaran, M., Holcomb, L. A., Hitt, A. R., Tharakan, B., Porter, J. W., Young, K. A., and Manyam, B. V. (2009). Centella asiatica extract selectively decreases amyloid beta levels in hippocampus of Alzheimer's disease animal model. Phytother. Res. 23, 14-19.

Dharmananda, S. (2004). Kampo Medicine - The Practice of Chinese Herbal Medicine in Japan. Portland. OR: Institute for Traditional Medicine.

Drever, B. D., Anderson, W. G., Riedel, G., Kim, D. H., Ryu, J. H., Choi, D. Y., and Platt, B. (2008). The seed extract of Cassia obtusifolia offers neuroprotection to mouse hippocampal cultures. J. Pharmacol. Sci. 107, 380-392.

Eckert, A., Keil, U., Scherping, I., Hauptmann, S., and Müller, W. E. (2005). Stabilization of mitochondrial membrane potential and improvement of neuronal energy metabolism by Ginkgo Biloba extract EGb 761. Ann. N. Y. Acad. Sci. 1056, 474-485.

Egashira, N., Iwasaki, K., Akiyoshi, Y., Takagaki, Y., Hatip-Al-Khatib, I., Mishima, K., Kurauchi, K., Ikeda, T., and Fujiwara, M. (2005). Protective effect of Toki-shakuyaku-san on amyloid beta25-35-induced neuronal damage in cultured rat cortical neurons. Phytother. Res. 19, 450-453.

Evans, J. G., Wilcock, G., and Birks, J. (2004). Evidence-based pharmacotherapy of Alzheimer's disease. Int. J. Neuropsychopharmacol. 7, 351-369.

Ferri, C. P., Prince, M., Brayne, C., Brodaty, H., Fratiglioni, L., Ganguli, M., Hall, K., Hasegawa, K., Hendrie, H., Huang, Y., Jorm, A., Mathers, C., Menezes, P. R., Rimmer, E., and Scazufca, M (2005). Global prevalence of dementia: a Delphi consensus study. Lancet 366, 2112-2117.

Fujiwara, H., Iwasaki, K., Furukawa, K., Seki, T., He, M., Maruyama, M., Tomita, N., Kudo, Y., Higuchi, M., Saido, T. C., Maeda, S., Takashima, A., Hara, M., Ohizumi, Y., and Arai, H. (2006). Uncaria rhynchophylla, a Chinese medicinal herb, has potent antiaggregation effects on Alzheimer's beta-amyloid proteins. J. Neurosci. Res. 84, 427-433.

Fujiwara, H., Tabuchi, M., Yamaguchi, T., Iwasaki, K., Furukawa, K., Sekiguchi, K., Ikarashi, Y., Kudo, Y., Higuchi, M. Saido, T. C., Maeda, S., Takashima, A. Hara, M., Yaegashi, N., Kase, Y., and Arai, H. (2009). A traditional medicinal herb Paeonia suffruticosa and its active constituent 1,2,3,4,6-penta- $O$ galloyl-beta-D-glucopyranose have potent anti-aggregation effects on Alzheimer's amyloid beta proteins in vitro and in vivo. J. Neurochem. 109, 1648-1657.

Garcia-Alloza, M., Dodwell, S. A., MeyerLuehmann, M., Hyman, B. T., and Bacskai, B. J. (2006). Plaque-derived oxidative stress mediates distorted neurite trajectories in the Alzheimer mouse model. J. Neuropathol. Exp. Neurol. 65, 1082-1089.

Haass, C., and Selkoe, D. J. (2007). Soluble protein oligomers in neurodegeneration: lessons from the Alzheimer's amyloid beta-peptide. Nat. Rev. Mol. Cell Biol. 8, 101-112.

Hayashi, Y., Ishida, Y., Inoue, T., Udagawa, M., Takeuchi, K., Yoshimuta, H., Kiue, K., Ninomiya, Y., Kawano, J., Sameshima, T., Kawahara, T., Goto, I., Shudo, K., Kurayama, S., Nakamura, J., Okahara, K., and Mitsuyama, Y. (2010). Treatment of behavioral and psychological symptoms of Alzheimer-type dementia with Yokukansan in clinical practice. Prog. Neuropsychopharmacol. Biol. Psychiatry 34, 541-545.

Heinrich, M. (2010). Galanthamine from Galanthus and other Amaryllidaceae-chemistry and biology based on traditional use. Alkaloids Chem. Biol. 68, 157-165.

Heinrich, M., and Lee Teoh, H. (2004) Galanthamine from snowdrop the development of a modern drug against Alzheimer's disease from local Caucasian knowledge. J. Ethnopharmacol. 92, 147-162.

Ho, Y. S., Yu, M. S., Yang, X. F., So, K. F., Yuen, W. H., and Chang, R. C. (2010). Neuroprotective effects of polysaccharides from wolfberry, the fruits of Lycium barbarum, against homocysteine-induced toxicity in rat cortical neurons. J. Alzheimers Dis. 19, 813-827.

Houghton, P. J., and Howes, M. J. (2005). Natural products and derivatives affecting neurotransmission relevant to Alzheimer's and Parkinson's disease. Neurosignals 14, 6-22.

Howes, M. J., Perry, N. S., and Houghton, P. J. (2003). Plants with traditional uses and activities, relevant to the management of Alzheimer's disease and other cognitive disorders. Phytother. Res. 17, 1-18.
Hsieh, C. L., Cheng, C. Y., Tsai, T. H., Lin, I. H., Liu, C. H., Chiang, S. Y., Lin, J. G., Lao, C. J., and Tang, N. Y. (2006). Paeonol reduced cerebral infarction involving the superoxide anion and microglia activation in ischemia-reperfusion injured rats. $J$ Ethnopharmacol. 106, 208-215.

Hsieh, C. L., Ho, T.Y., Su, S. Y., Lo, W.Y., Liu, C. H., and Tang, N. Y. (2009). Uncaria rhynchophylla and Rhynchophylline inhibit c-Jun $N$-terminal kinase phosphorylation and nuclear factorkappaB activity in kainic acid-treated rats. Am. J. Chin. Med. 37, 351-360.

Hu, Z. Y., Liu, G., Yuan, H., Yang, S., Zhou, W. X., Zhang, Y. X., and Qiao, S. Y. (2010). Danggui-Shaoyao-San and its active fraction JD-30 improve Abeta-induced spatial recognition deficits in mice. J. Ethnopharmacol. $128,365-372$.

Itoh, T., Michijiri, S., Murai, S., Saito, H. Nakamura, K., Itsukaichi, O., Fujiwara, H., and Ookubo, N. (1996). Regulatory effect of Danggui-Shaoyao-San on central cholinergic nervous system dysfunction in mice. Am. J. Chin. Med. 24, 205-217.

Iuvone, T., De Filippis, D., Esposito, G. D'Amico, A., and Izzo, A. A. (2006) The spice sage and its active ingredient rosmarinic acid protect $\mathrm{PC} 12$ cells from amyloid-beta peptide-induced neurotoxicity. J. Pharmacol. Exp. Ther. 317, 1143-1149.

Iwata, N., Tsubuki, S., Takaki, Y., Watanabe, K., Sekiguchi, M., Hosoki, E., Kawashima-Morishima, M., Lee, H. J., Hama, E., Sekine-Aizawa, Y., and Saido, T. C. (2000). Identification of the major Abeta1-42-degrading catabolic pathway in brain parenchyma: suppression leads to biochemical and pathological deposition. Nat. Med. 6, 143-150.

Jia, L., Zhao, Y., and Liang, X. J. (2009). Current evaluation of the millennium phytomedicine - ginseng (II): collected chemical entities, modern pharmacology, and clinical applications emanated from traditional Chinese medicine. Curr. Med. Chem. 16, 2924-2942.

Joshi, H., and Parle, M. (2006) Antiamnesic effects of Desmodium gangeticum in mice. Yakugaku Zasshi 126, 795-804.

Jung, J. W., Ahn, N. Y., Oh, H. R., Lee, B. K. Lee, K. J., Kim, S. Y., Cheong, J. H., and Ryu, J. H. (2006). Anxiolytic effects of the aqueous extract of Uncaria rhynchophylla. J. Ethnopharmacol. 108 193-197.

Kawasaki,T.,Yamanouchi,T.,Kashiwabara A., Inoue, T., Yoshimura, T., Fujimori S., Tanabe, T., and Aiso, Y. (2000). The influence of traditional Chinese herbal drugs on serum 1, 5-anhydroglucitol levels. Diabetes Res. Clin. Pract. 50, 97-101.

Kennedy, D. O., and Scholey, A. B. (2006). The psychopharmacology of European herbs with cognitionenhancing properties. Curr. Pharm. Des. 12, 4613-4623.

Kim, D. H., Hyun, S. K., Yoon, B. H., Seo, J. H., Lee, K. T., Cheong, J. H., Jung, S. Y., Jin, C., Choi, J. S., and Ryu, J. H. (2009). Gluco-obtusifolin and its aglycon, obtusifolin, attenuate scopolamine-induced memory impairment. J. Pharmacol. Sci. 111, 110-116.

Kimura, T., Hayashida, H., Furukawa, H., and Takamatsu, J. (2010). Pilot study of pharmacological treatment for frontotemporal dementia: effect of Yokukansan on behavioral symptoms. Psychiatry Clin. Neurosci. 64, 207-210.

Komatsu, M., Ueda, Y., and Hiramatsu, M. (1999). Different changes in concentrations of monoamines and their metabolites and amino acids in various brain regions by the herbal medicine/ Toki-Shakuyaku-San between female and male senescence-accelerated mice (SAMP8) [In Process Citation]. Neurochem. Res. 24, 825-831.

Kou, J., Zhu, D., and Yan, Y. (2005). Neuroprotective effects of the aqueous extract of the Chinese medicine Danggui-Shaoyao-san on aged mice. J. Ethnopharmacol. 97, 313-318.

Kumar, V. (2006). Potential medicinal plants for CNS disorders: an overview. Phytother. Res. 20, 1023-1035.

Lai, C. S., Yu, M. S., Yuen, W. H., So, K. F., Zee, S. Y., and Chang, R. C. (2008). Antagonizing beta-amyloid peptide neurotoxicity of the anti-aging fungus Ganoderma lucidum. Brain Res. 1190, 215-224.

Le Bars, P. L. (2003). Magnitude of effect and special approach to Ginkgo biloba extract EGb 761 in cognitive disorders. Pharmacopsychiatry 36(Suppl. 1), S44-S49.

Lee, C. L., Kuo, T. F., Wang, J. J., and Pan, T. M. (2007). Red mold rice ameliorates impairment of memory and learning ability in intracerebroventricular amyloid beta-infused rat by repressing amyloid beta accumulation. $J$. Neurosci. Res. 85, 3171-3182.

Lee, C. L., Kuo, T. F., Wu, C. L., Wang, J. J and Pan, T. M. (2010). Red mold rice promotes neuroprotective sAPPalpha secretion instead of Alzheimer's risk factors and amyloid beta expression in hyperlipidemic Abeta40-infused rats. J. Agric. Food Chem. 58, 2230-2238.

Lee, C. L., Tsai, T. Y., Wang, J. J., and Pan, T. M. (2006). In vivo hypolipidemic effects and safety of low dosage Monascus powder in a hamster model 
of hyperlipidemia. Appl. Microbiol. Biotechnol. 70, 533-540.

Lee, J., Son, D., Lee, P., Kim, D. K., Shin, M. C., Jang, M. H., Kim, C. J., Kim, Y. S., Kim, S. Y., and Kim, H. (2003). Protective effect of methanol extract of Uncaria rhynchophylla against excitotoxicity induced by $\mathrm{N}$-methylD-aspartate in rat hippocampus. $J$. Pharmacol. Sci. 92, 70-73.

Lee, J. S., Yoo, H., Suh, Y. G., Jung, J. K., and Kim, J. (2008). Structure-activity relationship of pentacylic triterpene esters from Uncaria rhynchophylla as inhibitors of phospholipase Cgammal. Planta Med. 74, 1481-1487.

Li, C., Yang, J., Yu, S., Chen, N., Xue, W., Hu, J., and Zhang, D. (2008a). Triterpenoid saponins with neuroprotective effects from the roots of Polygala tenuifolia. Planta Med. 74, 133-141.

Li, M. H., Chen, J. M., Peng, Y., Wu, Q., and Xiao, P. G. (2008b). Investigation of Danshen and related medicinal plants in China. J. Ethnopharmacol. 120, 419-426.

Lin, H. Q., Ho, M. T., Lau, L. S., Wong, K. K., Shaw, P. C., and Wan, D. C. (2008). Anti-acetylcholinesterase activities of traditional Chinese medicine for treating Alzheimer's disease. Chem. Biol. Interact. 175, 352-354.

Liu, P., Hu, Y., Guo, D. H., Lu, B. R., Rahman, K., Mu, L. H., and Wang, D. X. (2010a). Antioxidant activity of oligosaccharide ester extracted from Polygala tenuifolia roots in senescenceaccelerated mice. Pharm. Biol. 48, 828-833.

Liu, T., Jin, H., Sun, Q. R., Xu, J. H., and $\mathrm{Hu}, \mathrm{H} . \mathrm{T} .(2010 \mathrm{~b})$. The neuroprotective effects of Tanshinone IIA on beta-amyloid-induced toxicity in rat cortical neurons. Neuropharmacology $59,594-604$

Luo, C., Wu, Q., Huang, X. N., Sun, A. S., and Shi, J.S. (2003). Ginkgo biloba leaf extract enhances levels of caspase-3 and amyloid precursor protein in normal rat hippocampus. Acta Pharmacol. Sin. 24, 152-156.

Lv, J., Jia, H., Jiang, Y., Ruan, Y., Liu, Z., Yue, W., Beyreuther, K., Tu, P., and Zhang, D. (2009). Tenuifolin, an extract derived from tenuigenin, inhibits amyloid-beta secretion in vitro. Acta Physiol. (Oxf.) 196, 419-425.

Ma, J., Li, Y., Ye, Q., Li, J., Hua, Y., Ju, D., Zhang, D., Cooper, R., and Chang, M. (2000). Constituents of red yeast rice, a traditional Chinese food and medicine. J. Agric. Food Chem. 48, 5220-5225.

Maruyama, M., Tomita, N., Iwasaki, K., Ootsuki, M., Matsui, T., Nemoto, M., Okamura, N., Higuchi, M., Tsutsui, M., Suzuki, T., Seki, T., Kaneta, T., Furukawa, K., and Arai, H. (2006).
Benefits of combining donepezil plus traditional Japanese herbal medicine on cognition and brain perfusion in Alzheimer's disease: a 12-week observer-blind, donepezil monotherapy controlled trial.J. Am. Geriatr. Soc. 54, 869-871.

Mashkovsky, M. D., and Kruglikova-Lvov, R. P. (1951). On the pharmacology of the new alklaloid galantamine. Farmakol. Toxicol. (Moscow) 14, 27-30.

Mattson, M. P. (2004). Pathways towards and away from Alzheimer's disease. Nature 430, 631-639.

Mazza, M., Capuano, A., Bria, P., and Mazza, S. (2006). Ginkgo biloba and donepezil: a comparison in the treatment of Alzheimer's dementia in a randomized placebo-controlled double-blind study. Eur. J. Neurol. 13, 981-985.

Müller, W. E., Eckert, A., Kurz, C., Eckert, G. P., and Leuner, K. (2010). Mitochondrial dysfunction: common final pathway in brain aging and Alzheimer's disease - therapeutic aspects. Mol. Neurobiol. 41, 159-171.

Naito, R., and Tohda, C. (2006). Characterization of anti-neurodegenerative effects of Polygala tenuifolia in Abeta(25-35)-treated cortical neurons. Biol. Pharm. Bull. 29, 1892-1896.

$\mathrm{Ng}$, T. B. (2006). Pharmacological activity of sanchi ginseng (Panax notoginseng). J. Pharm. Pharmacol. 58, 1007-1019.

Nishizawa, K., Inoue, O., Saito, Y., and Suzuki, A. (1994). Protective effects of kamikihi-to, a traditional Chinese medicine, against cerebral ischemia, hypoxia and anoxia in mice and gerbils. Jpn. J. Pharmacol. 64, 171-177.

Oh, M. H., Houghton, P. J., Whang, W. K., and Cho, J. H. (2004). Screening of Korean herbal medicines used to improve cognitive function for anticholinesterase activity. Phytomedicine $11,544-548$.

Pendry, B., Busia, K., and Bell, C. M. (2005). Phytochemical evaluation of selected antioxidant-containing medicinal plants for use in the preparation of a herbal formula - a preliminary study. Chem. Biodivers. 2, 917-922.

Qian, Y. F., Wang, H., Yao, W. B., and Gao, X. D. (2008). Aqueous extract of the Chinese medicine, Danggui-ShaoyaoSan, inhibits apoptosis in hydrogen peroxide-induced PC12 cells by preventing cytochrome crelease and inactivating of caspase cascade. Cell Biol. Int. 32, 304-311.

Qiu, C., De Ronchi, D., and Fratiglioni, L. (2007). The epidemiology of the dementias: an update. Curr. Opin. Psychiatry 20, 380-385.

Qiu, C., Kivipelto, M., and von Strauss, E. (2009). Epidemiology of Alzheimer's disease: occurrence, determinants, and strategies toward intervention. Dialogues Clin. Neurosci. 11 111-128.

Ren, Y., Houghton, P., and Hider, R. C. (2006). Relevant activities of extracts and constituents of animals used in traditional Chinese medicine for central nervous system effects associated with Alzheimer's disease. J. Pharm. Pharmacol. 58, 989-996.

Ren, Y., Houghton, P. J., Hider, R. C., and Howes, M. J. (2004). Novel diterpenoid acetylcholinesterase inhibitors from Salvia miltiorhiza. Planta Med. 70, 201-204.

Schindowski, K., Leutner, S., Kressmann, S., Eckert, A., and Müller, W.E. (2001) Age-related increase of oxidative stressinduced apoptosis in mice prevention by Ginkgo biloba extract (EGb761). J. Neural Transm. 108, 969-978.

Sekiguchi, K., Yamaguchi, T., Tabuchi, M., Ikarashi,Y., and Kase, Y. (2009). Effects of yokukansan, a traditional Japanese medicine, on aggressiveness induced by intracerebroventricular injection of amyloid beta protein into mice. Phytother. Res. 23, 1175-1181.

Shi, J. S., Yu, J. X., Chen, X. P., and Xu, R. X. (2003). Pharmacological actions of Uncaria alkaloids, Rhynchophylline and Isorhynchophylline. Acta Pharmacol. Sin. 24, 97-101.

Stackman, R. W., Eckenstein, F., Frei, B. Kulhanek, D., Nowlin, J., and Quinn, J. F. (2003). Prevention of age-related spatial memory deficits in a transgenic mouse model of Alzheimer's disease by chronic Ginkgo biloba treatment. Exp. Neurol. 184, 510-520.

Stoll, S., Scheuer, K., Pohl, O., and Müller, W. E. (1996). Ginkgo biloba extract (EGb 761) independently improves changes in passive avoidance learning and brain membrane fluidity in the aging mouse. Pharmacopsychiatry 29, 144-149.

Sun, Y., Xie, T. T., Wang, D. X., and Liu, P. (2009). Effect of Polygala tenuifolia Willd YZ-50 on the mRNA expression of brain-derived neurotrophic factor and its receptor TrkB in rats with chronic stress depression. Nan Fang Yi Ke Da Xue Xue Bao 29, 1199-1203.

Tabuchi, M., Yamaguchi, T., Iizuka, S., Imamura, S., Ikarashi, Y., and Kase, Y. (2009). Ameliorative effects of yokukansan, a traditional Japanese medicine, on learning and noncognitive disturbances in the $\operatorname{Tg} 2576$ mouse model of Alzheimer's disease.J. Ethnopharmacol. 122, 157-162.

Tamura, T., Tohda, C., and Kamatsu, K. (2002). Therapeutic effects of Zokumei-to on spatial learning impairment and synaptic loss in a mouse model of Alzheimer's disease. Bull. Jpn. Soc. Neurochem. 41, 352.

Tang, W. K., Ungvari, G. S., and Leung, H. C. M. (2002). Effect of piracetam on ECT-induced cognitive disturbances: a randomized, placebo-controlled, double-blind study. J. ECT 18, 130-137.

Tohda, C., Naito, R., and Joyashiki, E. (2008). Kihi-to, a herbal traditional medicine, improves Abeta(25-35)induced memory impairment and losses of neurites and synapses. BMC Complement. Altern. Med. 8, 49. doi: 10.1186/1472-6882-8-49.

Tohda, C., Tamura, T., and Komatsu, K. (2003). Repair of amyloid beta(2535)-induced memory impairment and synaptic loss by a Kampo formula, Zokumei-to. Brain Res. 990, 141-147.

Tsolaki, M., Pantazi, T., and Kazis, A. (2001). Efficacy of acetylcholinesterase inhibitors versus nootropics in Alzheimer's disease: a retrospective longitudinal study. J. Int. Med. Res. $29,28-36$.

Tsuyoshi, M., and Jun, H. (2009). Clinical potential of Yi-Gan San (Yokukansan) for the treatment of psychiatric disorders. Curr. Psychiatry Rev. 5, 271-275.

Uabundit, N., Wattanathorn, J., Mucimapura, S., and Ingkaninan, $\mathrm{K}$. (2010). Cognitive enhancement and neuroprotective effects of Bacopa monnieri in Alzheimer's disease model. J. Ethnopharmacol. 127, 26-31.

Umeyama, A., Yahisa, Y., Okada, M., Okayama, E., Uda, A., Shoji, N., Lee, J. J., Takei, M., and Hashimoto T. (2010). Triterpene esters from Uncaria rhynchophylla drive potent IL-12-dependent Th1 polarization. J. Nat. Med. 64, 506-509.

Vasudevan, M., and Parle, M. (2009). Antiamnesic potential of Murraya koenigii leaves. Phytother. Res. 23, 308-316.

Veerendra Kumar, M. H., and Gupta, Y. K. (2003). Effect of Centella asiatica on cognition and oxidative stress in an intracerebroventricular streptozotocin model of Alzheimer's disease in rats. Clin. Exp. Pharmacol. Physiol. 30, 336-342.

Wang, T. H., and Lin, T. F. (2007). Monascus rice products. Adv. Food Nutr. Res. 53, 123-159.

Wang, Y. H., and Du, G. H. (2009). Ginsenoside Rg1 inhibits beta-secretase activity in vitro and protects against Abeta-induced cytotoxicity in PC12 cells. J. Asian. Nat. Prod. Res. $11,604-612$.

Watanabe, C. M., Wolffram, S., Ader, P., Rimbach, G., Packer, L., Maguire, J. J. Schultz, P. G., and Gohil, K. (2001). 
The in vivo neuromodulatory effects of the herbal medicine Ginkgo biloba. Proc. Natl. Acad. Sci. U.S.A. 98, 6577-6580.

Wimo, A., Winblad, B., Aguero-Torres, H., and von Strauss, E. (2003). The magnitude of dementia occurrence in the world. Alzheimer Dis. Assoc. Disord. 17, 63-67.

Xie, J. T., Chang, W. T., Wang, C. Z., Mehendale, S. R., Li, J., Ambihaipahar, R., Ambihaipahar, U., Fong, H.H., and Yuan, C.S. (2006). Curry leaf (Murraya koenigii Spreng.) reduces blood cholesterol and glucose levels in ob/ob mice. Am. J. Chin. Med. 34, 279-284.

Xu, Y., Cao, Z., Khan, I., and Luo, Y. (2008). Gotu Kola (Centella Asiatica) extract enhances phosphorylation of cyclic AMP response element binding protein in neuroblastoma cells expressing amyloid beta peptide. J. Alzheimers Dis. 13, 341-349.

Xue, W., Hu, J. F., Yuan, Y. H., Sun, J. D., Li, B. Y., Zhang, D. M., Li, C. J., and Chen, N. H. (2009). Polygalasaponin XXXII from Polygala tenuifolia root improves hippocampal-dependent learning and memory. Acta Pharmacol. Sin. 30, 1211-1219.
Yabe, T., Tuchida, H., Kiyohara, H., Takeda, T., and Yamada, H. (2003). Induction of NGF synthesis in astrocytes by onjisaponins of Polygala tenuifolia, constituents of kampo (Japanese herbal) medicine, Ninjin-yoei-to. Phytomedicine 10, 106-114.

Yamaguchi, K., Kido, H., Kawakatsu, T., Fukuroi, T., Suzuki, M., Yanabu, M., Nomura, S., Kokawa, T., and Yasunaga, K. (1993). Effects of kami-kihi-to (jiawei-gui-pi-tang) on autoantibodies in patients with chronic immune thrombocytopenic purpura. Am. J. Chin. Med. 21, 251-255.

Yan, H., Li, L., and Tang, X. C. (2007). Treating senile dementia with traditional Chinese medicine. Clin Interv Aging 2, 201-208.

Yang, L., Hao, J., Zhang, J., Xia, W., Dong, X., Hu, X., Kong, F., and Cui, X. (2009). Ginsenoside Rg3 promotes beta-amyloid peptide degradation by enhancing gene expression of neprilysin. J. Pharm. Pharmacol. 61, 375-380.

Yao, Z. X., Drieu, K., and Papadopoulos, V. (2001). The Ginkgo biloba extract EGb 761 rescues the PC12 neuronal cells from beta-amyloid-induced cell death by inhibiting the formation of beta-amyloid-derived diffusible neurotoxic ligands. Brain Res. 889, 181-190.

Yin, Y., Huang, L., Liu, Y., Huang, S., Zhuang, J., Chen, X., Zhang, L., Wu, H., Shao, F., and Zhao, Z. (2008). Effect of tanshinone on the levels of nitric oxide synthase and acetylcholinesterase in the brain of Alzheimer's disease rat model. Clin. Invest. Med. 31, E248-E257.

Yu, M. S., Leung, S. K., Lai, S. W., Che, C. M., Zee, S.Y., So, K. F., Yuen, W.H., and Chang, R. C. (2005). Neuroprotective effects of anti-aging oriental medicine Lycium barbarum against betaamyloid peptide neurotoxicity. Exp. Gerontol. 40, 716-727.

Yuen, M. F., Tam, S., Fung, J., Wong, D. K., Wong, B. C., and Lai, C. L. (2006). Traditional Chinese medicine causing hepatotoxicity in patients with chronic hepatitis B infection: a 1-year prospective study. Aliment. Pharmacol. Ther. 24, 1179-1186.

Zhou, Y. Q., Yang, Z. L., Xu, L., Li, P., and Hu, Y. Z. (2009). Akebia saponin D, a saponin component from Dipsacus asper Wall, protects PC 12 cells against amyloid-beta induced cytotoxicity. Cell Biol. Int. 33, 1102-1110.
Ziegler-Graham, K., Brookmeyer, R., Johnson, E., and Arrighi, H. M. (2008). Worldwide variation in the doubling time of Alzheimer's disease incidence rates. Alzheimers Dement, 4, 316-323.

Conflict of Interest Statement: The author declares that the research was conducted in the absence of any commercial or financial relationships that could be construed as a potential conflict of interest.

Received: 13 September 2010; accepted: 03 November 2010; published online: 08 December 2010.

Citation: Eckert GP (2010) Traditional used plants against cognitive decline and Alzheimer disease. Front. Pharmacol. 1:138. doi: 10.3389/fphar.2010.00138

This article was submitted to Frontiers in Ethnopharmacology, a specialty of Frontiers in Pharmacology.

Copyright (C) 2010 Eckert. This is an openaccess article subject to an exclusive license agreement between the authors and the Frontiers Research Foundation, which permits unrestricted use, distribution, and reproduction in any medium, provided the original authors and source are credited. 